\title{
598 LOCAL RADIATION IN COMBINATION WITH CPG AND ANTI-OX40 INDUCES ENHANCED T CELL ACTIVATION AND PROLIFERATION
}

${ }^{1}$ Dan Spiegelman*, ${ }^{1}$ Alexander Pieper, 'Luke Zangl, ${ }^{1}$ Arika Feils, ${ }^{1}$ Anna Hoefges, ${ }^{1}$ Mildred Felder, 'Sritha Moram, ${ }^{1}$ Alexander Rakhmilevich, ${ }^{1}$ Amy Erbe, ${ }^{1}$ Jacquelyn Hank, ${ }^{2}$ Ravi Patel, 'Zachary Morris, 'Paul Sondel. ' University of Wisconsin-Madison, Madison, WI, USA; ${ }^{2}$ University of Pittsburgh, Pittsburgh, PA, USA

Background We, and others, have previously shown that the in-situ vaccine of hypomethylated CG-enriched oligodeoxynucleotide $(\mathrm{CpG})$ with agonist anti-OX40 antibody (OX40) is effective at curing mice in the A20 lymphoma model [1-4]. In separate preclinical models where $\mathrm{CpG}+\mathrm{OX} 40$ fails to cause tumor regression, radiation therapy (RT) prior to the insitu vaccine enhances the anti-tumor effect of $\mathrm{CpG}+\mathrm{OX} 40$ [4]. We investigated the immune response, and specifically the activity of $\mathrm{T}$ cells, following treatment with $\mathrm{RT}+\mathrm{CpG}+\mathrm{OX} 40$ in the B78 melanoma model where $\mathrm{CpG}+\mathrm{OX} 40$ typically fails to cause tumor regression.

Methods C57BL/6 mice were inoculated with 2x106 B78 melanoma cells on the right flank and allowed to grow until the average tumor size was $\sim 150 \mathrm{~mm} 3$. In two independent experiments, mice were randomized $(n=4-5$ per group per experiment) and treated with one of the following: 1) PBS, 2) $\mathrm{CpG}+\mathrm{OX} 40$ ，3) RT，4) RT+CpG+OX40. 12 Gy external beam RT was dosed to the flank tumor on day 0 and intratumoral CpG $(50 \mu \mathrm{g})+\mathrm{OX} 40(20 \mu \mathrm{g})$ were given on days 5,7 , and 9 after RT. Spleens and tumor draining lymph nodes (TDLNs) were harvested on day 12 . T cell activation and proliferation were assessed via flow cytometry.

Results Compared to all other groups in the study, mice treated with $\mathrm{RT}+\mathrm{CpG}+\mathrm{OX} 40$ demonstrated significantly elevated levels of $\mathrm{CD} 4+$ and $\mathrm{CD} 8+\mathrm{T}$ cell activation in the TDLNs, as measured by interferon gamma expression. Similar trends of CD4+ and CD8 $+\mathrm{T}$ cell activation were measured in the spleens. Splenic CD8 $+\mathrm{T}$ cells from $\mathrm{RT}+\mathrm{CpG}+\mathrm{OX} 40$ treated mice demonstrated significantly elevated levels of proliferation over PBS and RT, as measured by Ki67.

Conclusions In B78 melanoma, a weakly immunologic tumor model, combining RT with the in-situ vaccine CpG+OX40 enhances the activity of $\mathrm{T}$ cells, evidenced by significantly increased $\mathrm{CD} 4+$ and $\mathrm{CD} 8+\mathrm{T}$ cell activation in the TDLN and spleen and elevated CD8 $+\mathrm{T}$ cell proliferation in the spleen.

\section{REFERENCES}

1. Houot, R. and Levy, R. T-cell modulation combined with intratumoral CpG cures lymphoma in a mouse model without the need for chemotherapy. Blood, 2009. $113(15): 3546-52$.

2. Marabelle, A., et al. Depleting tumor-specific Tregs at a single site eradicates disseminated tumors. J Clin Invest, 2013. 123(6):2447-63.

3. Sagiv-Barfi, I., et al. Eradication of spontaneous malignancy by local immunotherapy. Sci Transl Med, 2018. 10(426).

4. Zangl, LM. Et al. External Beam Radiotherapy Required for Tumor Regression When Using CpG-Oligodeoxynucleotide and Anti-OX40 in an Immunologically Cold Tumor Model. Red Journal. 2019. 105:S88.

http://dx.doi.org/10.1136/jitc-2021-SITC2021.598 